ИЗВЕСТИЯ АКАДЕМИИ НАУК ЭСТОНСКОИ ССР. ТОМ ІХ СЕРИЯ ФИЗИКО-МАТЕМАТИЧЕСКИХ И ТЕХНИЧЕСКИХ НАУК. 1960, № 4

\title{
К ВОПРОСУ РАЗВИТИЯ СТРУИ В СПУТНОМ ПОТОКЕ
}

\author{
Х. Суи
}

Ю. В. ИВАНОВ,

доктор технических наук

В наших прежних работах $\left[{ }^{1},{ }^{2}\right]$ были приведены основные закономерности затухания осевой скорости турбулентной круглой и плоской струи, развивающейся в спутном потоке. Установлено, что основным режимным параметром для изотермических струй является параметр $\lambda=v_{2} / v_{1}$, где $v_{2}$ - осевая скорость струи в устье и $v_{1}$ средняя скорость спутного потока. Опыты проводились со струями разных размеров. Отношение диаметра потока $D_{\text {п }}$ к диаметру сопла в устье $d$ или меньшему размеру плоского сопла $2 b_{0}$ составляло для круглых сопел от 22 до 70 и для плоских сопел от 250 до 580. Справедливость установленных закономерностей при сколь угодно больших значениях этого параметра не вызывает сомнений. Что же касается значений, меньших, чем нижний предел, то здесь требуется проведение дополнительных экспериментов. Следовательно, приведенные в работах $\left[{ }^{1},{ }^{2}\right]$ номограммы затухания осевой скорости круглой и плоской струи в спутном потоке справедливы для турбулентной струи любых размеров в пределах значений параметра $D_{n} / d$ и $D_{n} / 2 b_{0}$, равных и больше исследованных.

Как известно, при постановке опытов со струей в спутном потоке не удается получить ровный профиль скоростей основного потока по всему сечению на уровне среза сопла. В центральной области потока, непосредственно прилегающей к соплу, профиль скоростей обычно резко меняется.

В связи с тем, что это обстоятельство может поставить под сомнение универсальность полученных основных закономерностей затухания осевой скорости струи в спутном потоке, представляло как научный. так и практический интерес выяснение путем прямого опыта степени этого влияния. С этой целью при проведении некоторых опытов были предприняты попытки искусственно изменить значение скоростей потока вблизи круглого сопла.

На фиг. 1 приведены скоростные поля спутного потока в сечении среза устья круглых сопел двух размеров: $d=10,2$ и 20,2 мм. Из рисунка видно, что характер кривых, проведенных по опытным точкам, в различных точках неодинаков. В одних опытах скоростные поля довольно ровные и падение скорости у стенки сопла происходит почти мгновенно (фиг. $1 e, \nVdash, 3)$, в других - падение скорости происходит на более протяженном участке (фиг. $12, \partial$ ) и, наконец, в некоторых случаях кривая скоростей основного потока в районе устья струи даже превышает среднее значение скорости и падает лишь непосредственно у стенки сопла (фиг. $1 a, \sigma, 8)$. Результаты опытных данных по этим скоростным полям приведены в табл. 1. Таким образом, поставленные 
опыты позволили проследить влияние различий в скоростных полях на основные закономерности струи, развивающейся в спутном потоке.
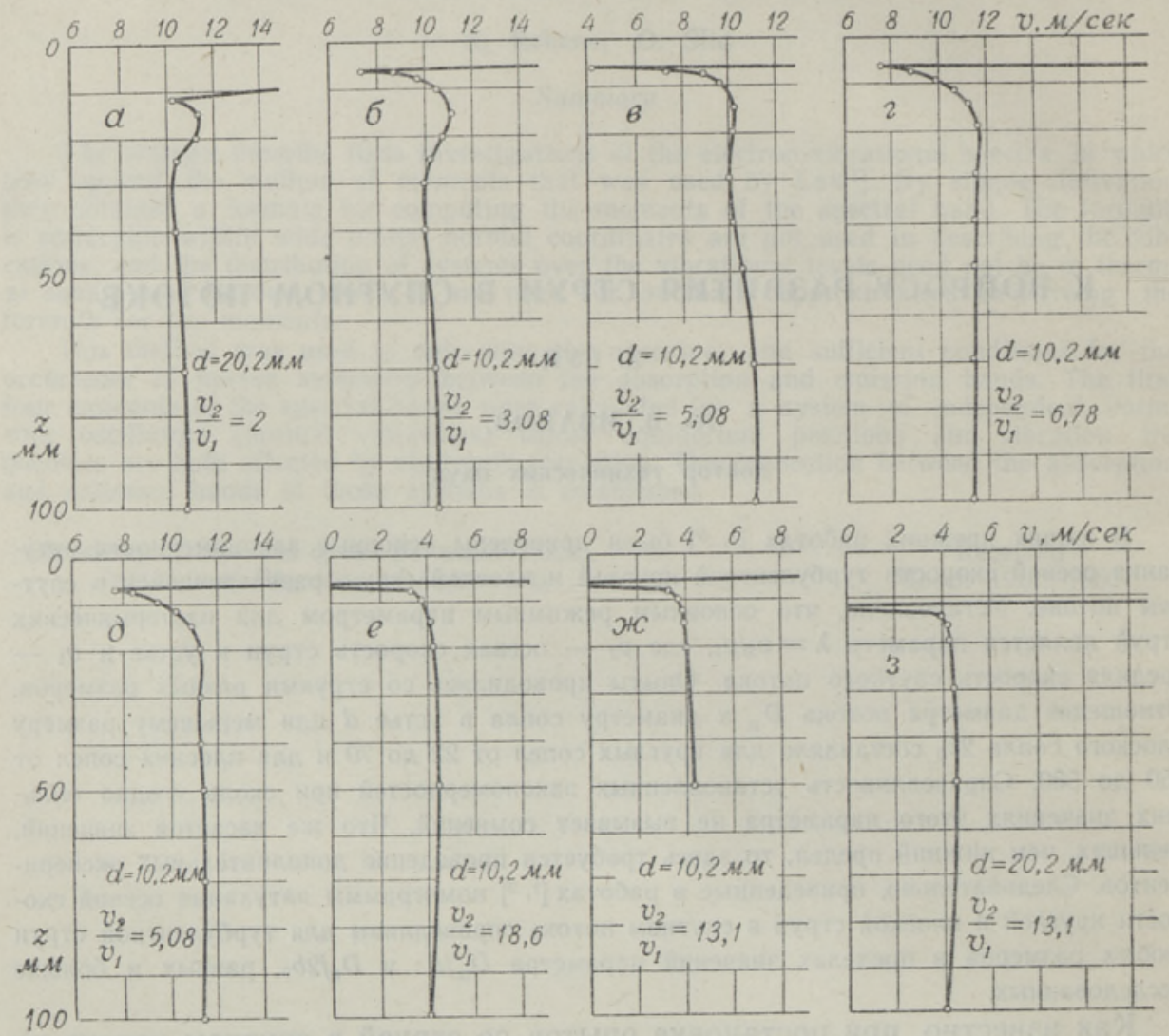

Фиг. 1. Скоростные поля спутного потока в сечении среза устья круглых сопел при различных значениях $d$ и $v_{2} / v_{1}$.

Далее рассмотрим опытные данные по струе в спутном потоке. На фиг. 2 приведено распределение по радиусу скоростей в поперечных сечениях струи и в потоке при значении $\lambda=13,1$. На верхнем графике фиг. 2 представлены профили скоростей для струи диаметром $d=10,2$ мм, а на нижнем - в том же масштабе для струи $d=20,2$ мм. Рассматривая преобразования скоростных полей в различных сечениях по мере их удаления от устья, можно на расстоянии примерно до 30 калибров различить границу струи в спутном потоке. Она характеризуется на каждой кривой точкой перехода, в районе которой скорость становится соизмеримой со средней скоростью потока. Координаты этой точки и принимались за.границу струи.

На фиг. 3 координаты границы струй диаметром 10,2 и 20,2 мм, представленные в относительных координатах, образуют единую линию: Согласно теории развития струи в спутном потоке, граница струи имеет криволинейную форму. Опытные данные показывают, что на коротком участке, равном примерно 30-40 калибрам, край струи можно принять прямолинейным и по углу расширения близким к углу свободной струи.

На фиг. 4 приведено сопоставление скоростных полей, замеренных в различных сечениях основного участка струи в спутном потоке. Из ри- 
Таблица 1

Скоростные поля струи и спутного потока в сечении среза сопла

\begin{tabular}{|c|c|c|c|c|c|c|c|c|}
\hline & $a$ & 6 & B & 2 & $\partial$ & $e$ & $\mathscr{H}$ & 3 \\
\hline $\begin{array}{l}v_{2}, \text { м/сек } \\
v_{1}, \text { м/сек } \\
\lambda \\
d, \text { мм } \\
D_{n}, \text { мм }\end{array}$ & $\begin{array}{r}21,2 \\
10,6 \\
2,0 \\
20,0 \\
450\end{array}$ & $\begin{array}{c}31,8 \\
10,3 \\
3,08 \\
10,2 \\
450\end{array}$ & $\begin{array}{c}52,4 \\
10,3 \\
5,08 \\
10,2 \\
450\end{array}$ & $\begin{array}{c}76,7 \\
11,3 \\
6,78 \\
10,2 \\
450\end{array}$ & $\begin{array}{c}58,0 \\
11,4 \\
5,08 \\
10,2 \\
450\end{array}$ & $\begin{array}{r}80,0 \\
4,3 \\
18,6 \\
10,2 \\
700\end{array}$ & $\begin{array}{r}56,4 \\
4,3 \\
13,1 \\
10,2 \\
700\end{array}$ & $\begin{array}{r}56,4 \\
4,3 \\
13,1 \\
20,2 \\
700\end{array}$ \\
\hline$x$, мм & 1 & 1 & 1 & 1 & 1 & 2 & 2 & 2 \\
\hline
\end{tabular}

\begin{tabular}{r|c|c|c|c|c|c|c|c}
0 & 21,2 & 31,8 & 52,4 & 76,5 & 58,0 & 80,0 & 56,4 & 56,4 \\
1 & - & - & - & 76,7 & 58,0 & 80,0 & 56,4 & - \\
2 & 21,2 & 31,8 & 52,4 & 76,7 & 58,0 & 79,5 & 56,4 & 56,4 \\
3 & - & - & - & 76,7 & 58,0 & 79,0 & 56,1 & - \\
4 & 21,2 & 29,9 & 49,0 & 73,6 & 56,8 & 78,0 & 54,0 & 56,3 \\
5 & - & 23,3 & 40,4 & - & - & 66,5 & 45,7 & - \\
6 & 21,2 & 7,2 & 4,2 & - & - & 24,7 & 0 & 56,2 \\
7 & - & 8,7 & 7,5 & 7,5 & 7,8 & 0 & 0 & - \\
8 & 21,1 & 9,7 & 9,1 & 8,9 & 8,6 & 3,6 & 3,4 & 55,5 \\
10 & 16,9 & 10,5 & 9,9 & 10,0 & 9,7 & 3,9 & 3,7 & 43,8 \\
12 & 10,4 & - & - & 10,7 & 10,4 & - & 3,8 & 0 \\
15 & 11,5 & 11,2 & 10,4 & 11,3 & 11,0 & 4,1 & 4,0 & 4,2 \\
20 & 11,4 & 10,8 & 10,3 & 11,6 & 11,4 & 4,3 & 4,2 & 4,4 \\
30 & 10,5 & 10,0 & 10,1 & 11,5 & 11,4 & - & - & 4,5 \\
40 & 10,4 & 10,0 & 10,3 & 11,6 & 11,6 & - & - & - \\
50 & 10,6 & 10,2 & 10,7 & 11,6 & 11,6 & 4,4 & 4,4 & 4,6 \\
70 & 10,8 & 10,5 & 11,1 & 11,5 & 11,7 & - & - & - \\
100 & 10,8 & 10,5 & 11,2 & 11,4 & 11,7 & 4,1 & - & 4,2
\end{tabular}

сунка видно, что опытные точки вполне удовлетворительно образуюг плавные кривые на всем исследованном участке.

Эти же данные, обработанные в относительных координатах, приведены на фиг. 5 в виде функции

$$
\frac{\Delta v}{\Delta v_{m}}=f\left(\frac{z}{z_{\mathrm{cp}}}\right)
$$

По оси ординат отложены безразмерные отношения значения избыточной скорости $\Delta v / \Delta v_{m}$, где $\Delta v=v-v_{1}-$ избыточная скорость в данной точке любого сечения по радиусу струи по отношению к скорости спутного потока; $\Delta v_{m}$ - избыточная скорость на оси в любом сечении струи.

На оси абсцисс нанесены безразмерные отношения $z / z_{\mathrm{cp}}$, где $z$ расстояние от оси до данной точки, а $z_{\text {cp }}$ - от оси до такой точки, в которой $\Delta v / \Delta v_{m}=0,5$.

На этом же рисунке сплошной линией нанесен для сравнения теоретический профиль струи в спутном потоке. Теоретический профиль на фиг. 5 соответствует закону для профиля скорости в струйном пограничном слое

$$
f(\eta)=\left(1-\eta^{3 / 2}\right)^{2},
$$

который впервые встречается в работе Шлихтинга $\left.{ }^{3}\right]$ по теории турбулентного следа за плохо обтекаемым телом. Согласно предложению Абрамовича $\left.{ }^{4}\right]$, этот закон можно использовать для облегчения даль- 

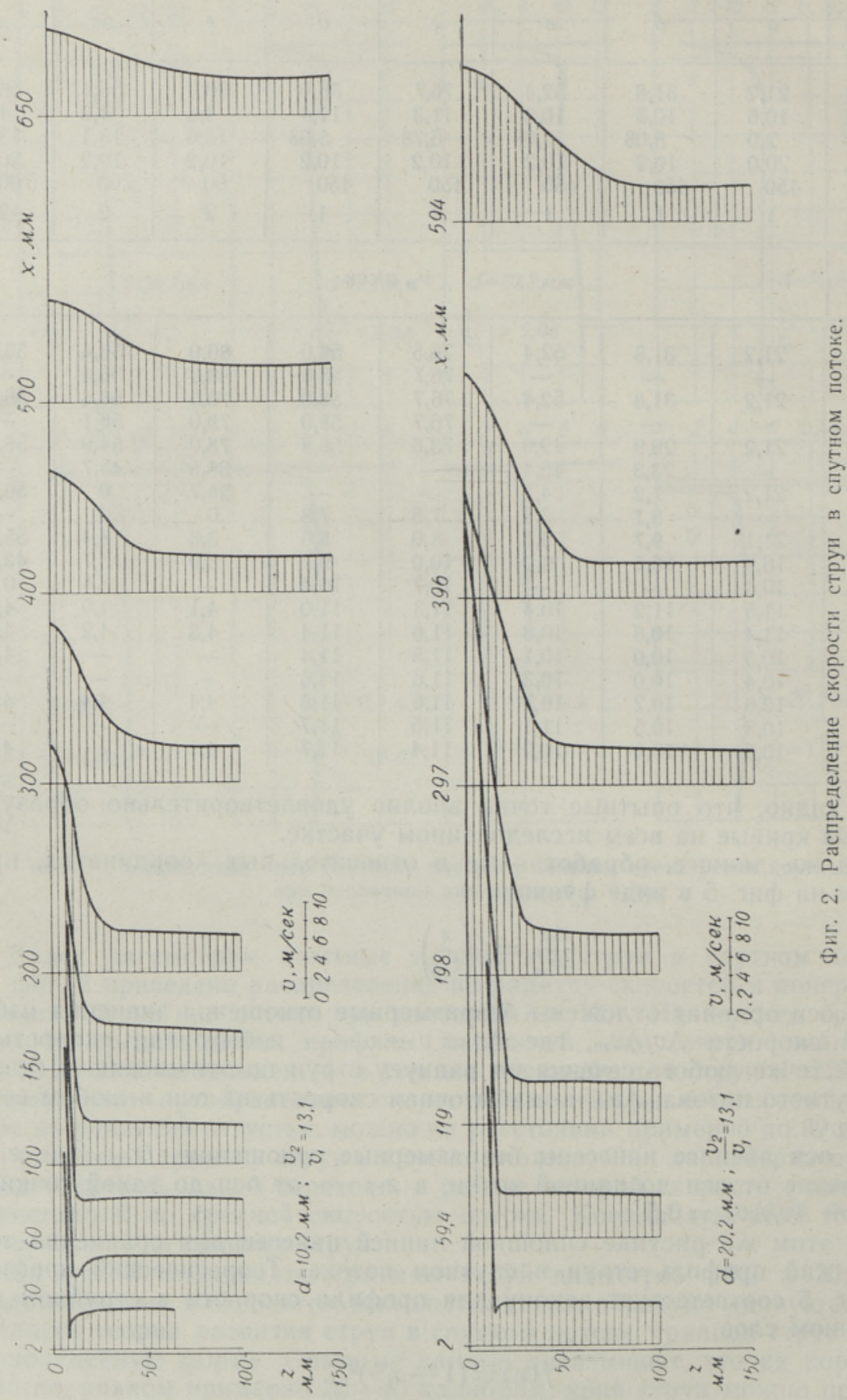
нейшего вычисления профиля скорости струи в спутном потоке. Тогда, после соответствующих подстановок,

$$
\frac{\Delta v}{\Delta v_{m}}=\left[1-\left(\frac{z}{b}\right)^{3 / 2}\right]^{2}
$$

где $z$ - расстояние от оси струи; $b$ - полуширина произвольного сечения основного участка струи.

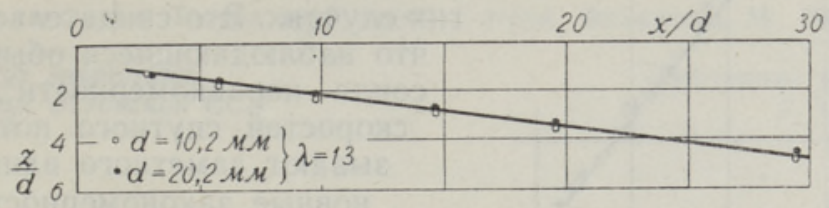

Фиг. 3. Край круглой струи в спутном потоке.

На фиг. 5 видно, что экспериментальные данные и теоретический профиль удовлетворительно совпадают во всем интервале, за исключением области $z / z_{\text {ср }}$ от 0 до 0,5 , где кривая скоростного профиля струи, проведенная на основании экспериментальных данных, проходит несколько выше теоретической.
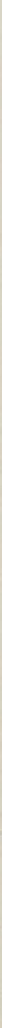

Фиг. 4. Распределение скоростей по радиусу круглой струи в спутном потоке.

Как уже отмечалось, опыты со струями различных диаметров проводились в спутном потоке, имеющем неодинаковый профиль скоростей у среза сопла. Поэтому представляло интерес проследить, как такие условия сказываются на затухании осевых скоростей струй. 


\title{
Л ИТ Е Р А Т Р А
}

1. Ю. В. Иван ов, Х. Н. Суй, Исследование развития струи в спутном потоке, Изв. АН ЭССР. Серия техн. и физ.-мат. наук, т. VII, № 2, 1958.

2. Х. Н. С уй, Ю. В. И в а нов, Исследование развития круглой струи в начальном участке встречной струи большего размера, Изв. АН ЭССР. Серия техн. и физ.-мат. наук, т. VIII, № 2, 1959.

3. H. S ch li cht ing, Ueber das ebene Windschattenproblem, Ing.-Arch., Nr. 5, 1930.

4. Г. Н. Аб р а м о в.и ч, Теория турбулентных струй, Физматгиз, М., 1960.

\author{
Институт энергетики \\ Академии наук Эстонской ССР \\ Поступила в редакцию \\ 1. VI 1960
}

\section{OHUJOA LEVIMISEST SAMASUUNALISES VOOLUSES}

\section{H. Sui}

\author{
J. Ivanov, \\ tehnikadoktor
}

\section{Resümee}

Artiklis käsitletakse samasuunalises vooluses leviva ümara õhujoa seaduspärasuste kehtivust niisugusel juhul, kus düüsi suudme lähedal vooluse kiirusteväli ei ole täiesti ühtlane.

Uurimistöö tulemused näitavad, et see ebaühtlus ei avalda märgatavat mõju joa levimise põhilistele seaduspärasustele. Sellepärast võib pōhjendatult kinnitada, et töödes ['] ja [ $\left.{ }^{2}\right]$ toodud valemid ning joa telgkiiruse muutumise nomogrammid omavad universaalset iseloomu.
Eesti NSV Teaduste Akadeemia Energeetika Instituut
Saabus toimetusse
1. VI 1960

\section{ON THE PROBLEM OF THE DEVELOPMENT OF A JET IN A CO-STREAM}

\author{
H. Sui, J. Ivanov
}

\section{Summary}

The authors present the results of their experimental studies of a round jet in a co-stream in the presence of irregularities of the velocities in the section of the orifice Experiments have shown that the irregularities in the range of the velocities near the wall of the orifice, which usually occur during the experiments, have no marked influence on the basic natural development of the jet in a co-stream. Therefore it has been possible to ascertain that the nomograms for the extinction of the axial velocity of a jet in a co-stream presented in the studies 1 and 2 as well as the computation formulae possess a universal character and can be related not only to jets tested in a co-stream in the presence of irregularities in the velocity range.

Academy of Sciences of the Estonian S.S.R., Institute of Energetics 